\title{
LA PERVIVENCIA DE LA MEMORIA. DE LA LUCHA CONTRA EL OLVIDO A LAS ACTITUDES DE POSRESISTENCIA AL FRANQUISMO EN ANDALUCÍA
}

\author{
Francisco Javier Giráldez Díaz y Miguel Ángel Melero Vargas \\ Doctores en Historia Contemporánea \\ giraldez2009@gmail.com \\ melerovargas@hotmail.com
}

\section{Resumen:}

El siguiente texto pretende llevar a cabo una aproximación a las distintas actuaciones Memoriales en Andalucía desde el golpe militar de julio de 1936, insistiendo no sólo en las estrategias de resistencia pasiva, aún no-forzada, al régimen y en la asimetría intencionada en relación con la reparación, sino también en cómo esos procesos han condicionado en los últimos cuarenta años la ausencia o el desarrollo de políticas públicas de Memoria, incidiendo en la evolución de la Memoria desde la perspectiva de las víctimas y su relación con el poder.

En este sentido, hemos querido reflexionar también en la forma en la que se ha planteado la lucha contra el Olvido, como prolegómeno de los propios movimientos de recuperación de la Memoria, centrándonos en las intervenciones en fosas desde la transición, la creación y preservación de los espacios de Memoria y la resignificación de los espacios del horror; o las políticas públicas de Memoria, producto de la presión positiva y el principio de colaboración de los soportes que la sustentan.

\section{Palabras clave}

Memoria - Víctimas - Represión Franquista - Políticas Públicas de Memoria - Exhumaciones

\begin{abstract}
:
The following text is intended to carry out an approach to the different actions memorials in Andalusia sinde the military coup of July 1936, emphasizing not only passive resistance strategies, even nonforced, the regime, and the intentional asymmetry in relation to the repair, but also in how those processes have conditioned in the past forty years the absence or the development of public policies of memory, influencing the evolution of the memory from the perspective of the victims and their relations to power.

In this sense, we wanted to also reflect on the way in which the fight against forgetting has been, as a preface of the movements themselves of recovery of memory, focusing on interventions in mass graves since the transition, creation and preservation of memory, spaces and the resignification of space of horror, or public policy in memory, a product of positive pressure and the principle of collaboration between the brackets that support it.
\end{abstract}

\section{Keywords:}

Memory - Victims - Francoist Repression - Public Policies of Memory - Exhumations 


\title{
LA PERVIVENCIA DE LA MEMORIA. DE LA LUCHA CONTRA EL OLVIDO A LAS ACTITUDES DE POSRESISTENCIA AL FRANQUISMO EN ANDALUCÍA
}

\author{
Francisco Javier Giráldez Díaz y Miguel Ángel Melero Vargas \\ giraldez2009@gmail.com \\ melerovargas@hotmail.com
}

Lo que se intenta abordar en este texto es un bíbrido del estado de la cuestión como justificación de nuestro trabajo desde la multi-óptica de familiares de víctimas, historiadores, miembros de colectivos Memorialistas y ahora responsables del desarrollo de políticas públicas de Memoria que somos, con el objetivo de clarificar y señalar en lo posible desde el análisis crítico el camino de las políticas públicas de Memoria a través del estudio de las distintas formas de reparación que han tenido las víctimas de la represión franquista en Andalucía durante ochenta años.

\section{Introducción: Memoria de unos, ¿Memoria de otros?}

La victoria sublevada en la guerra civil española a partir de abril de 1939 no sólo iba a traer el castigo, en sus múltiples manifestaciones, a los vencidos que quedaron vivos, sino que por extensión iba a propiciar una absoluta asimetría en cuanto al tratamiento de las víctimas, según fueran de uno u otro bando.

No en vano la región andaluza fue la más castigada por la represión franquista, lo que puede situarla como paradigma para afrontar el estudio de las diferentes manifestaciones de recuerdo y de resistencia al franquismo a través de la pervivencia de la Memoria de los vencidos: una región que según los últimos estudios contó con 57.413 personas asesinadas por los golpistas, frente a las 8.715 víctimas que causó la represión en zona republicana ${ }^{1}$.

A éstos habría que sumar los más de 6.000 masones represaliados por los Tribunales para la Represión de la Masonería y el Comunismo ${ }^{2}$, los casi 60.000 exiliados $^{3}$, miles de mujeres vejadas en su honor e intimidad, los miles de represaliados por el Tribunal de Orden Público, etcétera. Es decir, un balance represivo que puede servir de base para entender la transcendencia de la Memoria y el tratamiento del recuerdo de los vencidos a lo largo de 80 años.

El caso es que mientras que unas víctimas, las denominadas como mártires y caídos del bando sublevado, habían sido en su mayoría recuperadas, identificadas, enterradas de forma digna y honradas -al margen de las prebendas económicas y laborales percibidas por sus familiares-, las otras, salvo contadas excepciones, fueron desaparecidas y arrojadas a la indignidad de una fosa común, donde muchas de

\footnotetext{
${ }^{1}$ Fernández, Carmen y Giráldez, Francisco Javier, "La represión física en Andalucía", en Martínez, Fernando y Gómez, Miguel (coord.), La Memoria de todos. Las heridas del pasado se curan con más verdad, Sevilla, Fundación Alfonso Perales, 2014, pág. 52. Por otro lado, de las casi 58.000 víctimas de la represión física, entre el 12 y el 14\% lo fueron después de abril de 1939, lo que demuestra que la mayoría de los asesinatos se llevaron a cabo auspiciados por los bandos de guerra, sin incoación de procedimiento, de forma especialmente ilegal. Giráldez, Francisco Javier, Política y Memoria en la bistoria reciente de Andalucía, Universidad de Sevilla, Tesis doctoral inédita, 2014, pág. 5.

2 Álvarez, Leandro y Martínez, Fernando (eds.), La masonería en Andalucia y la represión durante el franquismo, Madrid, Biblioteca Nueva, 2017.

${ }^{3}$ Martínez, Fernando (coord.), Los andaluces en el exilio del 39, Sevilla, Centro de Estudios Andaluces, 2014.
} 
ellas siguen.

Con la ocupación progresiva de los territorios leales a la República y con el final de la guerra, el proceso de depuración desarrollado por las autoridades militares y grupos paramilitares, vino acompañado del proyecto del Nuevo Estado de construcción de su proceso de legitimación intentando, al igual que otros muchos regímenes totalitarios que implementaron la violencia y el terror como forma de control social, establecer su particular estrategia de evitación del Olvido y de construcción y mantenimiento de una Memoria oficial, unívoca y excluyente con los vencidos; una verdad de los vencedores, una posverdad ${ }^{4}$ franquista.

Lo hizo a partir de la construcción de un relato sesgado que ensalzaba la conspiración, la sublevación y la guerra y demonizaba el proyecto republicano y sus protagonistas, artífices de una España caótica sobre la que era preciso retornar el orden y los valores tradicionales que un día la hicieron grande ${ }^{5}$. Y lo hizo a través de una bibliografía hagiográfica, de la prensa, del panfletario falangista, o de la creación de su particular Comisión de la Verdad que fue la Causa General ${ }^{6}$.

Lo extrapoló también al marco geográfico más inmediato común a vencedores y vencidos, a partir de la absoluta ocupación del espacio público, con la omnipresente en todos los pueblos y ciudades Cruz de los Caídos $^{7}$, los monumentos dedicados a los artífices de la conspiración y la sublevación, las inscripciones, encabezadas por José Antonio Primo de Rivera, en las iglesias donde proliferaban los actos de acción de gracias y desagravio, los nombres de las calles, los edificios oficiales, y en definitiva con todo aquello que sirviera para recordar y potenciar el papel y destino asignado a cada uno de ellos en esta Nueva España.

${ }^{4}$ Una interesante reflexión acerca del término de posverdaden Gallego, Javier, 'Por qué lo llaman 'posverdad' cuando quieren decir "mentira", en línea en http://www.eldiario.es/carnecruda/lo-llevamos-crudo/llaman-posverdad-quieren-decirmentira 6 590800932.html.

${ }_{5}^{5}$ Melero, Miguel Ángel, De la Esperanza al sometimiento. Frente Popular, guerra civil y primer franquismo en una ciudad andaluza. El caso de Antequera, Málaga, Tesis doctoral inédita, 2013.

6 Con la progresiva ocupación de los pueblos y ciudades que dejaban de formar parte de la retaguardia republicana, la Junta de Defensa Nacional de Burgos iba a sacar la primera de una saga de publicaciones, en las que iban a compilarse las investigaciones desarrolladas por militares sublevados, pertenecientes al Cuerpo Judicial como forenses, y con la intención de plasmar las diferentes manifestaciones de la violencia desarrollada en ésta, aunque haciendo especial hincapié en los asesinatos cometidos. Así, este primer "Avance del informe oficial sobre los asesinatos, violaciones, incendios y demás depredaciones y violencias cometidos en algunos pueblos del mediodía de España por las hordas marxistas al servicio del llamado Gobierno de Madrid”, publicado por la imprenta sevillana Gavidia, y que hacía referencia además a Andalucía, y en concreto a diversos municipios de las provincias de Córdoba, Sevilla y Huelva recogerá, no solo la descripción pormenorizada de los sucesos acaecidos en estos municipios hasta su ocupación, sino sobre todo la impresión gráfica de un detallado anexo fotográfico que iba a plasmar de forma contundente el ejercicio de la represión en la retaguardia republicana contra aquellos que habían mostrado sus reservas y animadversión a los postulados republicanos, como falangistas, personas de derechas, propietarios y clero. Este primer avance, como los cuatro restantes que se publiquen hasta 1937, ya bajo la advocación de Estado Español van a suponer el inicio de la preparatoria sublevada encaminada, no solo a investigar estos excesos para su conocimiento, sino para mostrarlos al pueblo en toda su crudeza, e implicar a éste a fuerza de recordatorios, pero sobre todo para establecer sobre ellos la base justificadora de una voraz maquinaria represiva, de violencia y de venganza, desarrollada desde julio de 1936, y a medida que las sucesivas victorias militares les llevaban a una progresiva ocupación de territorio republicano, legal y gubernativo.

Una labor para la que no escatimarán acciones como la exhumación y publicación de fotografías de cadáveres, en una gran parte de ellos ya momificados e irreconocibles, así como de aquellos en los que se mostraran como evidentes, signos de tortura y violencia extrema. La "brutalización del enemigo", el reflejo gráfico de sus peores instintos y su uso propagandístico constituirían el acopio necesario para los sublevados para proseguir y aumentar su comportamiento genocida y de terror paralelo a su avance militar. Unos avances que, sin embargo, no son más que eso, una introducción, un prólogo a un proyecto mucho más ambicioso y extenso en el tiempo: la Causa General. Melero, Miguel Ángel, "Papeles franquistas al servicio de la memoria histórica. Investigación histórica y jurídica a través de la 'Causa General'. El caso de la comarca andaluza de Antequera (Málaga)", en I Congreso Internacional Investigación histórica, política y jurídica en torno la Memoria Histórica en España, Cáceres 2013.

7 Arco, Miguel Ángel del, "Las cruces de los caídos: instrumento nacionalizador en la "cultura de la victoria", en ÍD. et al. (eds.), No solo miedo. Actitudes políticas y opinión popular bajo la dictadura franquista, 1936-1976, Granada, Comares, 2013, págs. 6582. Melero, Miguel Ángel, De la Esperanza al sometimiento... op. cit. 
Lo confirmó casi veinte años después de finalizada la guerra cuando el 23 de mayo de 1958 Camilo Alonso Vega, Ministro de la Gobernación y Presidente del Consejo de las Obras del Monumento Nacional a los Caídos, solicitara la colaboración de las fuerzas vivas de cada municipio de España para que republicanos asesinados y enterrados en fosas comunes de todo el país, fueran exhumados y enterrados en el de nuevo de actualidad en estos días Valle de los Caídos ${ }^{8}$, y convirtiéndolo en un monumento a la reconciliación nacional a partir de la piedad franquista. Un latrocinio en el que fueron de nuevo ultrajados los cuerpos de casi 34.000 vencidos. Y lo sigue haciendo, por ejemplo, a día de hoy, con la labor de entidades privadas - pero con aportación de dinero público- como la Fundación Francisco Franco.

Esta asimetría mantenida desde hace más de ocho décadas, sobre todo en cuanto a la consideración y tratamiento de las víctimas, y en especial a las que yacían en enterramientos ilegales, llevó por ejemplo, desde la guerra y a lo largo de la dictadura, a la ocultación y/o destrucción de muchas fosas comunes? con el claro objetivo de"aplicación de una Memoria preventiva que comienza con el borrado o la confusión de las evidencias”"10.

Una asimetría que es precisamente también la clave que tienen a día de hoy en común tanto los detractores como los defensores del hito de la Recuperación de la Memoria Histórica en España, en su formato más conocido como movimiento social surgido al amparo de ese punto de inflexión que fue la exhumación en la localidad leonesa de Priaranza del Bierzo, en octubre de 2000, de los restos de trece civiles asesinados por falangistas en 1936, y que dio lugar a la creación de la Asociación para la Recuperación de la Memoria Histórica en España. Los primeros, conocedores de esa geografía del terror, y con el objetivo de mantener su Memoria imperante, por acudir al argumentario del revanchismo, la reapertura de heridas, el interés económico o la ruptura de los pactos de la Transición -preceptos, por cierto, insuflados desde el principio por la derecha española, y reavivados a día de hoy por el actual Gobierno de España-, y los segundos por entender que se trataba meramente de una cuestión básica de justicia y derechos humanos, a partir de un proyecto de dignificación física, de reparación moral, y de construcción de un relato objetivo que permitiera conocer y difundir la verdad, y combatir con ella el Olvido.

Estas acciones, como decíamos, experimentaron un impulso decisivo coincidiendo con el cambio de siglo y milenio, como si por ello una especie de suerte sideral hubiera provocado una remoción en las conciencias, o una dotación de herramientas y un manual de estilo hasta ese momento impensables, pero ancladas sin embargo en muchos años atrás, incluso en aquellos en que probablemente aún no era necesaria la Memoria, sino más bien la transmisión del recuerdo a las generaciones posteriores, pues para unos el terror era el presente y para otros España vivía una particular re-fundación, un Año Cero $^{11}$ donde el pasado parecía no haber existido nunca.

\section{Memoria coetánea y resistencia}

"Los secretos son eso, secretos que nunca pueden ser confesados", debía lamentarse Modesta Vázquez cuando cada día, desde el 27 de febrero de 1938, repetía de manera obsesiva el mismo recorrido, aquel que le llevaba desde el municipio onubense de Zalamea la Real, a través de la carretera que une éste con

\footnotetext{
8 En mayo de 2017, una Proposición No de Ley presentada por el Partido Socialista Obrero Español (PSOE) en la Comisión Constitucional, y aprobada sin votos en contra, establece instar al Gobierno a sacar del Valle de los Caídos los restos de Francisco Franco. Véase http://politica.elpais.com/politica/2017/05/11/actualidad/1494486625 806861.html.

${ }^{9}$ Así por ejemplo en el Cementerio de San José de Almería, Rodríguez, Óscar, Informe sobre la localización de los restos óseos de las víctimas del franquismo fusiladas y enterradas en el cementerio de San José y Santa Adela, Almería, Dirección General de Memoria Democrática de la Consejería de Cultura de la Junta de Andalucía, 2016. Puede ser consultado en http://juntadeandalucia.es/organismos/cultura/areas/Memoria-democratica/fosas/paginas/informe-actuaciones.html.

${ }^{10}$ Ferrándiz, Francisco, El pasado bajo tierra. Exhumaciones contemporáneas de la guerra civil, Madrid, Anthropos, 2014, pág. 50.

${ }^{11}$ Box, Zira, España, Año Cero: la construcción simbólica del franquismo, Madrid, Alianza Editorial, 2010.
} 
el vecino pueblo de Calañas para desviarse, a menos de un kilómetro del pueblo, a una vía pecuaria situada en el paraje conocido como Valle Redondo, y en cuya margen derecha, a unos cien metros según se bajaba, depositaba flores frescas en la tumba improvisada de Ramón, su marido.

Quizás también bajaba a diario para cerciorarse de que ni el agua, ni las variaciones que pueden producirse en un terreno tan maleable como este arcilloso, ni tan siquiera el olvido provocado por quien quiere que se oculte el delito, habían movido de su sitio, ni las piedras que señalaban los límites de la tumba, ni la cruz de hierro que la coronaba. Repetiría esta acción, incansable, casi de forma fantasmagórica y enajenada, durante cuatro décadas, cuando otros tomaran el relevo en la vigilancia de la conocida ya en todo el pueblo como "fosa del marido de la Modestita".

Anarquista y miembro del Comité de Guerra de Zalamea en los días del conflicto civil en la retaguardia republicana, Ramón Delgado había huido del pueblo, como tantos otros, temeroso de las represalias que sobre él pudieran aplicar las tropas sublevadas que lo ocuparon el 25 de agosto de 1936.

Sin embargo, agotado por la mala vida en la sierra, donde se había refugiado, Ramón decidió volver a casa en enero de 1937. Permaneció un año escondido hasta que su mujer, profundamente religiosa, y buscando desesperadamente soluciones que pudieran aliviar el ostracismo de su marido, confesó al cura del pueblo su paradero, y le pidió su intercesión para poder llevar a cabo una "entrega controlada y segura"de éste. No tardó, a pesar de ello, en acudir un grupo de guardias civiles y falangistas a su casa, donde fue apresado Ramón a finales de enero de 1938, y acusado, según la declaración de varios vecinos, de ser un "individuo peligroso, por sus ideas marxistas, para la Causa Nacional". El 26 de febrero de 1938 Ramón Delgado, en compañía del ugetista Juan Manuel Guerrero, fue sacado de la cárcel y trasladado a Valle Redondo, muriendo ambos como consecuencia de los disparos de sus captores, "cuando intentaban huir". ${ }^{12}$

La propia Modesta, que supo también lo que fue pasar por el filtro de una Justicia Militar que ordenó su detención por encubrimiento y que terminó absolviéndola por ser "muy religiosa y de derechas"13, mandó a su padre a seguir al grupo que llevaba a su marido y al compañero de éste a la muerte, para que después de la ejecución y una vez abandonados a flor de tierra, enterrara sus cuerpos, precisamente el de Ramón con una cruz colgada al cuello que la propia Modesta le había dado. Allí permanecerían hasta que 77 años después, en 2015, la voluntad de "cumplir con el encargo" por parte de Ramón Romero, sobrino de Ramón y Modesta, unida a la colaboración del movimiento Memorialista, el apoyo de las administraciones y en última instancia el trabajo de un equipo multidisciplinar de historiadores, arqueólogos y antropólogos, posibilitara el inicio de los trabajos que a finales de ese año llevarían a la localización de la fosa, la recuperación de los cuerpos y su entierro digno.

A casi 150 kilómetros de Zalamea la Real y en el mismo contexto de ocupación y represión sublevada, Máximo González Mariscal había sido una de las 144 víctimas mortales que los últimos estudios establecen para el caso de la localidad sevillana de Guadalcanal, entre asesinados por Bando de guerra, desaparecidos, ejecutados por sentencia firme de Consejo de Guerra, o muertos por la Guardia Civil, entre otros ${ }^{14}$. (JMGM, 2012, las víctimas de la represión militar...).

Le diferenciaba del resto de víctimas el hecho de que su padre, a pesar de todo con cierto ascendente social y consideración entre las nuevas autoridades franquistas, hubiera conseguido, aún con mucho esfuerzo, comprar un pequeño espacio de terreno en el Cementerio municipal de San Francisco, entre dos panteones familiares, a sabiendas de que coincidiría con la ubicación de la única fosa común conocida en el municipio. Sobre ella colocaron una lápida con la inscripción "González Olivera y Familia”, que serviría de protección para el futuro, no sólo para el cuerpo de Máximo, sino para los de

\footnotetext{
12 Alcántara, Cristóbal y Fernández, Andrés, Informe. Exbumación de fosa común en Valle Redondo, Zalamea la Real, Huelva, Dirección General de Memoria Democrática de la Consejería de Cultura de la Junta de Andalucía, 2015.

13 Alcántara, Cristóbal y Fernández, Andrés, Informe. Exhumación de fosa común en V alle Redondo... op. cit.

${ }^{14}$ García, José María, Las víctimas de la represión militar en la provincia de Sevilla (1936-1963), Sevilla, Aconcagua, 2012.
} 
seis víctimas más de Guadalcanal y Ahillones, en la provincia de Badajoz, y asesinados entre el 19 -día de la ocupación del municipio- y el 23 de agosto de $1936^{15}$.

Una protección que posibilitó que justo 80 años después, María González, hermana aún viva de Máximo, casi centenaria pero con envidiable lucidez y fortaleza, autorizara expresamente una intervención arqueológica que en el tiempo en que se escribe este artículo ya estaba dando sus primeros resultados satisfactorios.

Casi treinta años más tarde de que tuvieran lugar los hechos de estos dos primeros sitios, Rosa Arjona acompañaba desde muy pequeña cada 7 de mayo a su madre, a llevar al cementerio de Villanueva de la Concepción, en Málaga, un ramo de flores en el que predominaban el rojo, el amarillo y el morado.

"La de banderas republicanas que habré puesto yo cuando no podían ponerse", reía sin rencor Rosa, que sabía, como ella misma dice, que esos ramos un día "dejarían de ser furtivos". ${ }^{16}$

Otros vecinos, mucho antes que ella y en una etapa en la que llevar flores a una tumba tan incómoda ya resultaba en sí misma una acción desafiante y subversiva para un pueblo en el que las conocidas como "bijas de Pilar" - por Pilar Primo de Rivera, fundadora y dirigente de esta organización-, acudían cada mañana a las puertas de las casas de los rojos regresados tras la ocupación de Málaga para despertarles a golpe de nota del himno falangista Cara al Sol, las tiraban sin embargo desde fuera de la tapia más meridional del cementerio, con toda la precisión posible para que cayeran encima del enterramiento colectivo e ilegal que aún a día de hoy albergaría los cuerpos de 17 vecinos del pueblo.

Era la única forma, esta teledirigida, que tenían de poder mantener el recuerdo, el homenaje y de alguna manera la resistencia frente al franquismo, en un punto en el que la resiliencia como forma de supervivencia no resultaba suficiente para los vencidos y, para colmo, silenciados ${ }^{17}$.

Nada hasta aquí distorsionaba de los comportamientos mimetizados y extrapolables de unos casos a otros que, a partir de la progresiva ocupación de territorios leales a la República primero, como desde el final de la guerra después, desarrollaron cada uno de los actores intervinientes en el proceso, así fueran promotores, ejecutores, colaboradores o destinatarios de la represión y la violencia ${ }^{18}$ : La trampa de la inexistencia de castigos a los que no hubieran cometido delitos de sangre, la participación de una parte de la población parapolicial, vigilante y delatora ${ }^{19}$-por cierto, de nuevo con la ambigüedad y poca consistencia en las acusaciones-, sobre otra vencida, y el papel de ambas en la represión cotidiana y la vejación y el apartamiento hacia la segunda; también el papel de la Iglesia católica como colaboradora necesaria de aquellos que habían convenido mostrar la sublevación y la guerra como una Cruzada contra los enemigos de Dios ${ }^{20}$, o el papel de los grupos parapoliciales y paramilitares como ejecutores directos de la represión en su máximo exponente.

\footnotetext{
15 Gómez, Ignacio, Guadalcanal Siglo XX. 1931-1940, Sevilla, 2016. García, José María, La UGT de Sevilla. Golpe militar, resistencia y represión (1936-1950), Sevilla, Fundación para el Desarrollo de los Pueblos de Andalucía, 2008. Carrasco, Inmaculada (coord.), Proyecto de intervención. Recuperación de los restos de represaliados a consecuencia del Golpe de Estado de 1936. Guadalcanal (Sevilla), Dirección General de Memoria Democrática de la Consejería de Cultura de la Junta de Andalucía, 2016.

16 Testimonio de Rosa Arjona en el Homenaje a las víctimas por la libertad y la democracia celebrado en Villanueva de la Concepción el 7 de mayo de 2017.

17 De las diferentes actitudes ciudadanas frente al franquismo ya hemos tenido oportunidad de reflexionar en las páginas de esta revista, en Melero, Miguel Ángel, "Alineamiento, indiferencia y formas de resistencia ante el Nuevo Estado franquista en los primeros años del terror, 1936-1945”, en Contenciosa, año II, 3, segundo semestre de 2014. Por otro lado, alguno de los títulos más recientes donde se aborda también este de un tiempo a esta parte, prolífico campo de estudio, en Prada, Julio (dir.), No solo represión. La construcción del franquismo en Galicia, Madrid, Biblioteca Nueva, 2014.

18 Gil, Carlos: "También hombres del pueblo. Colaboración ciudadana en la gran represión", en Arco, Miguel Ángel del, No sólo miedo...op. cit. pág. 51. Melero, Miguel Ángel, "Caras de un proceso poliédrico: Nuevos enfoques sobre las actitudes ante la represión franquista", en Actas del Congreso Posguerras. 75 Aniversario Fin de la Guerra Civil, Madrid, Fundación Pablo Iglesias, 2015.

${ }^{19}$ Melero, Miguel Ángel, "Alineamiento, indiferencia...", op. cit.

${ }^{20}$ Rodrigo, Javier, Cruzada, Paz, Memoria, Granada, Comares, 2013.
} 
Y por supuesto las víctimas directas de la represión y sus familias, condenadas unas a la indignidad de una cuneta o con un poco de suerte a la zona más marginal de un cementerio como destino final de sus cuerpos, y sometidas las otras al escarnio público, el exilio interior y el dolor callado.

Sin embargo estos tres breves ejemplos, que debieron ser muchos más, demuestran cómo una parte de la población vencida no se conformaría con su rol de doliente silenciosa y que, quizás casi sin pretenderlo, pero de forma coetánea al contexto del terror, había iniciado un proceso de (pre)recuperación de la Memoria, que no era otro que el de la lucha contra el Olvido, al menos en su proyección pública, como de preparación del terreno a una Memoria que debería llegar después, lo que suponía también de alguna forma una actitud de resistencia al franquismo en el sentido de desafiar la obsesión de los victimarios por laminar, con la desaparición de los cuerpos, cualquier rastro de todo aquello que hubiera tenido que ver con el proyecto republicano iniciado en 1931.

La clave residía efectivamente en la tierra, y con ella en la señalización y mantenimiento, siquiera como subterfugio, de los espacios del horror, para su posterior conversión en espacios de recuerdo. Porque si para unos la forma más fácil de borrar la huella del crimen era hacer desaparecer los cuerpos, la única esperanza de sus dolientes era que no murieran de nuevo a través del Olvido, y la forma más fácil de olvido era la de no disponer un sitio al que ir a llorar la ausencia y rendir homenaje a través del único vínculo físico de unos huesos, que era lo mismo que no poder conseguir cerrar su círculo del duelo. Por eso la obsesión por mantener la ubicación, como brújula para la traslación generacional de la Memoria, por la que de alguna manera estos pioneros estaban preparando el terreno para los descendientes que hoy transitan, con independencia de su punto de origen, por los recodos de un complejo mapa Memorialista.

Porque si a algo nos aventuran estos ejemplos es a plantearnos que quizás la Memoria, por ser coetánea al horror, nunca se fue, o que la recuperación de la misma comenzó, no exenta incluso de un halo de heroicidad, en el mismo momento en que ésta comenzó a estar en peligro, esto es, mucho antes de lo que oficialmente ha sido registrado, si bien con una dificultad inversamente proporcional al éxito y eficacia de su cometido entonces, pero ya con la certeza de que la clave residía en no dejar que se perdieran $-\mathrm{y}$ por tanto se olvidaran- los sitios -y desde luego con ellos los cuerpos-, en espera de un futuro más halagüeño que permitiera llegar a la esencia: la recuperación física de las víctimas directas de la represión y su entierro digno, la reparación moral de sus víctimas subsidiarias, y el cierre definitivo del círculo del duelo para las generaciones pasadas, presentes y futuras.

\section{De la Transición al fin del Siglo de los Genocidios ${ }^{21}$}

No fueron éstos los únicos ejemplos de lucha de mínimos contra el Olvido y (pre)Memoria, que se dieron en Andalucía, y que en su gran mayoría no llegaron a pasar de este nivel de resistencia encubierta como forma de supervivencia desde la resiliencia, en una realidad política y social asfixiantes, durante casi cuarenta años. Algunos sin embargo fueron más allá, con el acometimiento de exhumaciones clandestinas llevadas a cabo por los propios familiares durante la Dictadura.

En otros casos, fueron los ayuntamientos franquistas los encargados de llevar a cabo actuaciones de exhumación, fundamentalmente por la clausura de los cementerios o por la necesidad de desarrollar obras de ampliación, trasladando los restos a un osario general o inhumándolos en nichos sin especificar.

Pero por lo general fueron cuatro décadas de "negación de la Memoria"22 de los vencidos por parte de los poderes públicos, paralela además a la persecución de éstos ${ }^{23}$, donde los únicos restos exhumados y

\footnotetext{
${ }^{21}$ Bruneteau, Bernard, El siglo de los genocidios. Violencias, masacres y procesos genocidas, Madrid, Alianza Editorial, 2006.

${ }_{22}^{2}$ Espinosa, Francisco, Contra el olvido: historia y Memoria de la guerra civil, Barcelona, Planeta, 2006.

${ }^{23}$ Giráldez, Francisco Javier, Política y Memoria...op. cit., pág. 6.
} 
recuperados, al margen de las mencionadas intervenciones clandestinas, fueron los de aquellos que formaron parte del ya mencionado traslado al Valle de los Caídos, y para el que se desarrollaron 18 intervenciones en fosas en Andalucía. ${ }^{24}$

Llegaría después el final de la dictadura, y el desarrollo de un periodo de Transición a la Democracia escrutado de forma severa por los que consideran que ésta se forjó en unas condiciones beneficiosas para la derecha ${ }^{25}$, por traer aparejada una política de olvido de la Memoria y que estableció, fundamentalmente con la conocida Ley de Amnistía de $1977^{26}$, una equidistancia sobre la guerra civil y la dictadura, que potenciaba la impunidad de los victimarios y dejaba en el desamparo de la Historia a las víctimas y sus familias ${ }^{27 .}$

Será en este sentido donde la conformación de los primeros ayuntamientos democráticos, después de las elecciones municipales de 1979, contribuirá a fortalecer, desde las administraciones más cercanas a los familiares de las víctimas, la colaboración de éstas a la exhumación -ciertamente con mucha más voluntad que ciencia- y enterramiento digno de sus seres queridos, y la señalización y monumentalización de las fosas en que se hallaban como primeros lugares de la Memoria.

Así ocurriría por ejemplo a mediados de diciembre de 1979 en Jimena de la Frontera, cuando el Partido Socialista Obrero Español (PSOE) de este municipio gaditano decidió, en consonancia con los familiares, el inicio de los trámites necesarios para la exhumación, después de cuarenta y tres años, de los restos de cuatro vecinos asesinados a la salida del pueblo en noviembre de $1936^{28}$, o incluso un año antes en el municipio de La Carolina, donde se constituyó una Comisión de Familiares de víctimas republicanas que en enero de 1978 solicitó al Alcalde de la localidad jienense las autorizaciones para poder exhumar a sus familiares, la cesión de un nuevo espacio al que poder trasladar sus restos y la construcción de un mausoleo que sirviera de recuerdo y homenaje a las víctimas; un proceso que culminaría felizmente en noviembre de ese mismo año. ${ }^{29}$

Especialmente significativo es el caso del municipio sevillano de Constantina, donde según información del grupo de investigación Todos los Nombres se exhumaron entre 1979 y 1980 los restos de más de setecientas víctimas de una fosa común. En total se:

“...lograron rescatar más de 780 calaveras y multitud de huesos con signos evidentes de muerte violenta. También se encontraron una gran cantidad de anillos, pendientes, cadenas... que fueron introducidos en las calaveras, éstas en bolsas de plástico y posteriormente en dos grandes arcones" 30

Dichos arcones con los restos se depositaron en el interior de un mausoleo a las víctimas de la guerra civil y de la represión franquista en la localidad.

Así sería en definitiva y hasta el año 2000, en 122 municipios de la comunidad andaluza ${ }^{31}$, culminando con éxito una acción colectiva de familiares de víctimas de la represión franquista que, partiendo de la

\footnotetext{
24 Producto del trabajo Mapa de Fosas de Andalucía, en línea en http://juntadeandalucia.es/organismos/cultura/areas/Memoria-democratica/fosas/mapa-fosas.html.

${ }_{25}$ Giráldez, Francisco Javier, Política y Memoria... op. cit., pág. 7.

${ }^{26}$ Ley 46 de Amnistía, del 15 de octubre de 1977, Boletín Oficial del Estado (BOE) 248, 17 de octubre de 1977.

${ }^{27}$ Así el propio Espinosa en su obra mencionada más arriba, o Ángel del Río, a los que contrarrestan en sus postulados otros especialistas como Santos Juliá. Véase Espinosa, Francisco, Contra el olvido... op. cit. Río, Ángel del, "Nuevos sentidos del pasado franquista. Las políticas de Memoria en Andalucía", en Escalera, Javier y Coca, Agustín, Movimientos sociales, participación y ciudadanía en Andalucía, Sevilla, Aconcagua, 2013, y Juliá, Santos, "De nuestras Memorias y de nuestras miserias", en Hispania Nova, 7, 2007, en línea en http://hispanianova.rediris.es.

${ }^{28}$ Collado, Pascual, "Palabras en el Homenaje al XXX aniversario de la exhumación de la Cruz Blanca en Jimena de la Frontera", en línea enhttp:// pascualcollado.blogspot.com.es/2010/11/palabras-en-el-homenaje-al-xxx.html

${ }^{29}$ Serrano, Juan, "La exhumación de 1979 en Murcia. Acción colectiva de familiares de fusilados republicanos durante la transición", Ayer, 103/2016 (3), Madrid, Marcial Pons, págs. 147-177.

30 Véase: http://www.todoslosnombres.org/sites/default/files/mapas fosas/fosas sevilla.pdf, pág. 76.

${ }^{31}$ Mapa de Fosas de Andalucía, op. cit.
} 
coincidencia en el espacio de la visita a la fosa, habían establecido un contacto que les llevó primero a consolidar unos lazos afectivos para luego, desde la construcción de una Memoria colectiva, a la agrupación con el objetivo de la recuperación de los cuerpos de sus deudos, dejando al descubierto de paso la prueba más palpable de la represión.

Había resultado además exitosa esa traslación generacional a la que antes aludíamos en cuanto a la conservación del espacio, manteniendo el recuerdo de las familias como arma contra el olvido que pretendió imponerse desde 1936 y que a la postre ha resultado decisiva para que en un 90\% de las 614 fosas documentadas en la región andaluza en 2009, según refleja el Mapa de Fosas de Andalucía ${ }^{32}$, las fuentes de información para su localización hayan procedido en su práctica totalidad de los testimonios orales, en muchos casos de los familiares. ${ }^{33}$

A partir de ahí el siguiente paso sería la solicitud de apoyo económico pero sobre todo burocrático a las recién estrenadas instituciones democráticas, en no pocos casos a partir de una actitud resiliente que, al menos en la esfera pública, llevó a los familiares agrupados a una actitud de des-politización y desideologización del proyecto, como forma de precaución ante una coyuntura política y socialmente compleja, si con ello lograban su objetivo.

En todo caso, eran puestas de realce algunas claves que guiarían desde ese momento las iniciativas de recuperación de víctimas de la guerra civil y la posguerra, y que a día de hoy constituyen el armazón de este proceso: la voluntad y el empuje de los familiares de las víctimas, el agrupamiento de los interesados en un objetivo común, el apoyo institucional, incluso la cobertura mediática, y en definitiva la visibilización de un proceso en continua progresión, y que volvería a contar con un nuevo punto de inflexión en el año 2000.

\section{E1 Siglo de la Memoria: de la iniciativa familiar a las políticas públicas de Memoria}

El tránsito al siglo XXI sirvió, a nivel mundial, para poner en el centro del debate sobre la Memoria nuevas perspectivas y enfoques en torno a los grandes conflictos del siglo XX. España, Polonia, los Balcanes, China, Japón, Guatemala, Chile, etcétera, han venido experimentando de unos años a esta parte y dentro de sus diferencias y especificidades, procesos de revisión de su pasado trágico, donde han aflorado debates en torno a temas tan trascendentes como las exhumaciones de fosas comunes ${ }^{34}$.

En el caso español, también el cambio de siglo pareció romper, de manera más contundente, los techos de cristal apuntalados en la Transición y primeros años de la Democracia en cuanto a la toma en consideración de las víctimas, si bien es cierto que no con la uniformidad deseada, generando importantes desequilibrios entre unas regiones y otras, en función del signo político del gobierno de turno.

Pero sí que existieron, a pesar de todo, cambios positivos de notable calado. Y es que el carácter

\footnotetext{
32 Resultado del trabajo conjunto de algunas de las principales entidades Memorialistas de Andalucía, las universidades públicas de la comunidad y el Gobierno regional, y con el objetivo de dar cumplimiento a lo dispuesto en la Ley 52/2007, de 26 de diciembre, en su Artículo 12.2, el Mapa de Fosas de Andalucía incluye información sobre 614 enterramientos ilegales documentados en toda la región. Presentado en 2009, los avances desarrollados desde entonces en materia de intervenciones en fosas como en la documentación relativa a la etapa de investigación, han propiciado modificaciones en la herramienta, y sobre las que trabajábamos en el tiempo en que redactábamos este artículo. A nivel estatal, y mediante Resolución de 27 de noviembre de 2009 de la Subsecretaría del Ministerio de la Presidencia, la Sociedad de Ciencias Aranzadi lleva a cabo el proyecto para realizar una base de datos con información integral de las fosas comunes exhumadas de la guerra civil, -BOE 2902 de diciembre de 2009-, bajo la dirección del Dr. Fco. Etxeberria Gabilondo, Profesor Titular de Medicina Legal y Forense de la Universidad del País Vasco, y como parte del proyecto de investigación "Las políticas de la Memoria en la España contemporánea: Análisis del impacto de las exbumaciones de la Guerra Civil en los primeros años del Siglo XXI”.

${ }^{33}$ Mapa de Fosas de Andalucía, op. cit.

${ }^{34}$ Ferrándiz, Francisco, El pasado bajo tierra. Exbumaciones contemporáneas de la Guerra Civil, Barcelona, Anthropos, 2014, pág. 16.
} 
poliédrico de la represión franquista iba a reflejarse también en las diferentes formas de reparación que han tenido las víctimas. La multitud y diversidad de las víctimas de la represión franquista ha provocado una respuesta confusa por parte de las administraciones públicas. Las políticas públicas de Memoria han sido variadas según las comunidades autónomas y por lo general se han caracterizado por una falta de continuidad, y desde luego por la ausencia, a excepción de la última legislatura del Gobierno de José Luis Rodríguez Zapatero (PSOE), de una Política de Estado para con la Memoria, generando una grave asimetría entre unas comunidades y otras, que quedaban a merced de políticas de partido con un carácter intermitente $^{35}$, o lo que es lo mismo el uso político de la Memoria como instrumento discriminatorio en base al alineamiento ideológico y de siglas.

En lo que respecta a Andalucía, y a excepción de iniciales disposiciones orientadas a la indemnización económica a ex-presos y represaliados políticos - con 9.533.145, $70 €$ para 2.491 beneficiarios entre 2001 y 201136- así como de forma específica a mujeres ultrajadas durante la guerra y la dictadura -con una dotación de $205.200 €$ para 114 beneficiarias $^{37}$-, era sin duda en la recuperación de los cuerpos donde se situaba la piedra angular del proceso ${ }^{38}$.

Así, la experiencia de casi un cuarto de siglo de intervenciones en fosas después del final de la dictadura había mostrado ciertas claves insoslayables de cara a establecer una hoja de ruta exitosa, sustentada en el principio de colaboración, y desde éste a la visibilización de un proceso que llevara a una concepción naturalizada y normalizada del mismo, a su asimilación, e incluso a un apoyo social generalizado.

Por contra el déficit se encontraba, sin ningún lugar a dudas, en dos planos absolutamente fundamentales y que con posterioridad tendrían un encaje adecuado: el técnico y el normativo. Qué, quién y cómo se haría.

Pero antes de esto se vislumbraba la homogeneización en el agrupamiento de los familiares de las víctimas, como parte de los prolegómenos para la intervención en una fosa de la guerra y el franquismo, lo que cristalizaría en el año 2000 con la creación de la Asociación para la Recuperación de la Memoria Histórica y el surgimiento de un Memorialismo militante, de claro sustrato familiar y sentimental, pero donde comenzarían también a aflorar las diferentes sensibilidades políticas -y que a la postre desencadenarían en una fractura dentro del movimiento Memorialista- que veían en la recuperación de la Memoria una vía de reivindicación de la historia -y sufrimiento durante la larga dictadura- de los principales partidos de izquierda, desde su ilegalización a partir de la Ley de Responsabilidades Politicas $^{39}$ a la persecución, encarcelamiento, expolio y muerte de una parte de su militancia, y que terminaría provocando importantes escisiones dentro del movimiento Memorialista. Y todo ello a pesar de que en el espacio puramente político se había establecido una clara sintonía entre los principales partidos de izquierda, por ejemplo cuando en noviembre de 2002 presentaran una serie de

35 Giraldez, Javier, Política y Memoria en la bistoria reciente de Andalucía, Universidad de Sevilla, Tesis doctoral inédita, Sevilla, 2014, pág. 10.

${ }^{36}$ Giraldez, Javier, Política y Memoria..., pág. 30.

${ }^{37}$ Giraldez, Javier, Política y Memoria...pág. 41.

38 Decreto $1 / 2001$, de 9 de enero, por el que se establecen indemnizaciones a ex-presos y represaliados políticos que sufrieron privación de libertad por más de tres años y se acuerda abrir convocatoria pública para aquellos otros que sufrieron privación de libertad por menos de tres años, ambos como consecuencia de los supuestos previstos en la Ley 46/1977, de 15 de octubre, de Amnistía, BOJA 11, 27 de enero de 2001. Decreto 333/2003, de 2 de diciembre, por el que se establecen indemnizaciones a ex-presos y represaliados políticos que sufrieron privación de libertad por un período superior a tres meses e inferior a tres años, como consecuencia de los supuestos previstos en la Ley 46/1977, de 15 de octubre, de Amnistía, Boletin Oficial de la Junta de Andalucía (BOJA) 236, 9 de diciembre de 2003. Decreto 35/2006, de 21 de febrero, por el que se establece el procedimiento de concesión de indemnización de cuantía única a las personas ex presas y represaliadas políticamente que sufrieron privación de libertad como consecuencia de los supuestos previstos en la Ley 46/1977, de 15 de octubre, de Amnistía y que no se acogieron a las indemnizaciones reguladas en los Decretos 1/2001, de 9 de enero, y 333/2003, de 2 de diciembre, BOJA 50, 15 de marzo de 2006, y Decreto 372/2010, de 21 de septiembre, por el que se establecen indemnizaciones a mujeres que sufrieron formas de represión de la dictadura franquistasobre su honor, intimidad y propia imagen, BOJA 200, 13 de octubre de 2010.

${ }^{39}$ Ley de 9 de febrero de 1939, de Responsabilidades Políticas, BOE 44, 13 de febrero de 1939. 
Proposiciones No de Ley sobre el reconocimiento y reparación de los familiares de las víctimas, y su derecho a recuperar sus restos. ${ }^{40}$

Para este tiempo también ya comenzaba a funcionar un embrionario desarrollo normativo en Andalucía que, como hicieran los propios familiares y las entidades Memorialistas, situaba la recuperación y reparación de las víctimas de la guerra civil y la dictadura, así como de alguna forma su reconocimiento social e institucional, en su principal objetivo, al margen de las que pudieran sustraerse de la Ley 5/1979, de 18 de septiembre ${ }^{41}$, referente a pensiones y asistencia médico-farmacéutica y social a familiares de víctimas de la guerra civil.

Así por ejemplo las ya mencionadas primeras indemnizaciones a ex-presos y represaliados políticos durante la guerra y la dictadura, o la articulación de un procedimiento orientado a establecer un primer intento de regulación técnica y administrativa relacionada con las actuaciones en fosas, desde el principio de colaboración de familiares, entidades Memorialistas y ayuntamientos con la administración andaluza, o la profesionalización de las intervenciones, con la participación de técnicos acordes con las tareas a realizar, esto es, historiadores, arqueólogos y antropólogos. ${ }^{42}$

El mensaje trasladado por los familiares de las víctimas, desde el propio 1936, y el testigo recogido por sus descendientes desde la Transición y en adelante, de que era en las fosas donde se encontraba la clave del proyecto contra el Olvido y por la recuperación de la Memoria Histórica, había llevado a que en Andalucía hubiera primado el desarrollo de instrumentos que regularan la intervención arqueológica, antesala de los protocolos que desde un lustro más tarde servirían para regular las pautas científicas y técnicas que aseguraran una adecuada intervención para la recuperación de los restos de las víctimas de la guerra civil y hasta su destino final ${ }^{43}$ sobre una unidad administrativa específica, dotada de presupuesto propio, y orientada a ser en esencia una oficina de atención a las víctimas del franquismo, como finalmente sería el Comisariado para la Recuperación de la Memoria Histórica ${ }^{44}$, redenominado posteriormente en la actual Dirección General de Memoria Democrática, pero con la misma esencia y competencias del primero.

Se había adelantado Andalucía al resto de comunidades, como al propio Gobierno del Estado, que en 2007 aprueba su conocida como Ley de Memoria Histórica ${ }^{45}$, motivo de nuevo de confrontación política, tanto por los que la consideraban innecesaria -por no decir incómoda-, y los que la sospechaban como insuficiente y de corto alcance en cuanto a su capacidad reparadora. Pero lo que no puede negársele es que implicara, por encima de todo, la voluntad de comenzar un camino que concluyera en el desarrollo de una Política de Estado para con la Memoria, desde la declaración de ilegitimidad de los tribunales militares franquistas y sus condenas, la mejora y diversificación de las indemnizaciones, la protección documental y el acceso a los archivos y la creación del Centro

\footnotetext{
40 Diario de sesiones del Congreso, 625, 20 de noviembre de 2002, 20502-20517.

${ }^{41}$ Ley 5/1979, de 18 de septiembre, sobre reconocimiento de pensiones, asistencia médico-farmacéutica y asistencia social en favor de las viudas, hijos y demás familiares de los españoles fallecidos como consecuencia o con ocasión de la pasada guerra civil. BOE 233, 28 de septiembre de 1979.

42 Decreto 334/2003, de 2 de diciembre, para la coordinación de actuaciones en torno a la recuperación de la Memoria histórica y el reconocimiento institucional y social de las personas desaparecidas durante la Guerra Civil Española y la Posguerra. BOJA 236, 9 de diciembre de 2003.

43 Orden de 7 de septiembre de 2009, BOJA 190, 28 de septiembre de 2009 y Orden PRE/2568/2011, de 26 de septiembre, BOE 232, 27 de septiembre de 2011. Este protocolo será también el que acompañe a los textos de otras comunidades, como el "Plan Vasco 2015-2020 de investigación y localización de fosas para la búsqueda e identificación de personas desaparecidas durante la Guerra Civil", elaborado por la Sociedad de Ciencias Aranzadi, o bien en última instancia la Ley 10/2016, de 13 de junio, para la recuperación de personas desaparecidas durante la Guerra Civil y el franquismo, Butlleti Oficial, Govern de les Illes Balears (BOIB), n. 76, 16 de junio de 2016.

${ }^{44}$ Decreto 54/2005, de 22 de febrero de 2005, por el que se crea la figura de Comisario para la recuperación de la Memoria Histórica, BOJA 40, 25 de febrero de 2005.

${ }^{45}$ Ley 52/2007, de 26 de diciembre, por la que se reconocen y amplían derechos y se establecen medidas en favor de quienes padecieron persecución o violencia durante la guerra civil y la dictadura, BOE 310, 27 de diciembre de 2007.
} 
Documental de la Memoria Histórica, el estudio y retirada de la simbología franquista, y por supuesto las medidas para la localización e identificación de las víctimas en las miles de fosas del país.

No obstante, la llegada del Partido Popular (PP) al Gobierno de España paralizaría todas las iniciativas, no llevando a cabo la derogación del texto pero sí a un coma inducido al desposeerlo totalmente, y de forma efectiva desde 2012, de presupuesto.

\section{Las víctimas del franquismo hoy: Asimetrías y Post-resistencias}

Desde el cambio de Gobierno en España, ya había pasado casi una década desde el inicio del Siglo de la Memoria, cuando comenzaron a funcionar "sucursales" provinciales de la Asociación para la Recuperación de la Memoria Histórica, y de su escisión, los Foros por la Memoria, así como casi el mismo tiempo desde que Andalucía comenzara a ser pionera en el desarrollo de políticas públicas en este sentido.

El caso es que desde este tiempo y hasta 2014, fecha en la que en Andalucía ya venía trabajándose desde hacía dos años sin ningún tipo de aportación económica por parte del Gobierno central, y donde desde este año además la línea de subvenciones en materia de recuperación de la memoria histórica, que desde su creación en 2004 incluía las actuaciones específicas en fosas ${ }^{46}$, pasaría a tener una partida presupuestaria propia, habían sido desarrolladas en esta región en torno a 60 intervenciones en enterramientos ilegales vinculados a la guerra civil y la posguerra, permitiendo la recuperación de en torno a 3.600 cuerpos de represaliados del franquismo ${ }^{47}$, y entre las que encontramos casos muy señeros como una de las tres que se ubican en el municipio gaditano de El Bosque, la primera de las exhumaciones ejecutadas con método arqueológico tras la aprobación del mencionado Decreto $334 / 2003$ y donde entre 2004 y 2005 fueron recuperadas entre 22 y 24 víctimas $^{48}$, la también gaditana de Grazalema con 16 víctimas (2008) o la sevillana de Gerena, con 17 (2011) donde las víctimas eran exclusivamente mujeres, la cordobesa de Aguilar de la Frontera (2010) que presentó una gran complejidad técnica para la exhumación de 65 cuerpos, la jerezana del cortijo de El Marrufo, donde 28 cuerpos fueron exhumados gracias al patrocinio privado de una conocida empresa ${ }^{49}$, la malagueña de Istán (2012), donde se obtuvo el beneplácito de los propietarios del terreno para poder exhumar los 4 cuerpos que la componían ${ }^{50}$; la onubense de Encinasola (2014) que concluyó de forma inmejorable con la identificación genética de las 3 víctimas exhumadas, o la de la mayor fosa común exhumada en España hasta la fecha, la del Antiguo Cementerio de San Rafael de Málaga, con 2.840 represaliados recuperados de los más de 4.000 registrados. $^{51}$

Las diferencias entre todas ellas radicaban en aspectos que iban desde el mero número y tipología de los represaliados, las sinergias que pudieran entablarse entre administraciones, las fuentes de

\footnotetext{
46 En el periodo comprendido entre 2004 y 2016, y a través de diez convocatorias de subvenciones, el importe destinado a Ayuntamientos -en líneas de difusión como de construcción de monumentos de Memoria-, proyectos de asociaciones Memorialistas -incluyendo las intervenciones en fosas- y fundaciones sindicales, así como de los puestos en marcha por parte de universidades, superó los 2.400.000 €. Giraldez, Javier, Política y Memoria... op. cit., pág. 30, así como de la información obtenida del personal del Servicio de Memoria Democrática de la Consejería de Cultura de la Junta de Andalucía.

${ }^{47}$ Elaboración propia en base a los datos aportados por el Mapa de Fosas de Andalucía, op. cit. Véase asimismo Giraldez, Javier, Política y Memoria... op. cit., pág. 218.

48 Román, Jesús, Memoria arqueológica de las fosas comunes en el cementerio de El Bosque, 2005.

${ }^{49}$ La Sauceda, de la utopía al horror, dirigido por Juan Miguel León y Juan Moriche, España, 2013, Foro por la Memoria del Campo de Gibraltar y Asociación de Familiares de Represaliados por el Franquismo en La Sauceda y el Marrufo.

${ }^{50}$ Foro por la Memoria de Andalucía, Trabajos de exbumación en la fosa de Istán, Comisariado para la Recuperación de la Memoria Histórica de la Junta de Andalucía, 2012.

${ }^{51}$ Fernández, Sebastián y Fernández, Andrés, Informe: Actuación arqueológica. Exbumación de restos humanos de las fosas comunes de la guerra civil y la posguerra. Antiguo cementerio de San Rafael (Málaga), Junta de Andalucía, Ayuntamiento de Málaga y Universidad de Málaga, 2009.
} 
financiación, la participación de los colectivos Memorialistas, o la implicación en su conjunto del entorno social más inmediato, pero todas habían tenido como denominador común en su origen la participación activa y voluntariosa de los familiares de las víctimas, decididos a ir en su búsqueda, recuperar sus cuerpos de la indignidad de una fosa común, y a ser posible arrebatar sus nombres al Olvido.

Esa mirada a través de los ojos de los familiares continuaría constituyendo la principal inspiración para las políticas públicas de Memoria desarrolladas en Andalucía en un nuevo periodo que se iniciaba en 2015 y en cuyo pleno desarrollo nos encontramos en la actualidad; más si cabe después de un lustro en el que la aportación económica para la aplicación de la Ley 52/2007 por parte del Gobierno de Mariano Rajoy (PP) ha sido eliminada en su totalidad.

Así, las iniciativas para las intervenciones en fosas en Andalucía, sobre todo desde 2011-2012 traían aparejadas, no sólo el objetivo primigenio y consciente de recuperación de restos de víctimas de la guerra y la posguerra, sino un remozamiento desde aquellas estrategias encubiertas para el no-Olvido por parte de las víctimas de hace casi 80 años, y que desde hace algunos años basculan hacia lo que podríamos definir como una actitud de "posresistencia" abierta frente un franquismo sociológico que aún pervive y, lo que es más grave, frente a unos gobiernos centrales de derechas como el de José María Aznar (1996-2004) ${ }^{52}$ o el mencionado de Mariano Rajoy (2011- actualidad) que, al contrario que países como Alemania, Argentina o Chile, han hecho de su negacionismo, o en el mejor de los casos, de su revisionismo equidistante, su particular política pública de Memoria, sustentada en el desprecio a una parte de aquellos a los que se debe como servidor público, las víctimas, y la negación de sus derechos a partir del incumplimiento de disposiciones como la Declaración sobre la protección de todas las personas contra las desapariciones forzadas, aprobada por la Asamblea General de Naciones Unidas en diciembre de $1992^{53}$, o las recomendaciones recogidas en el Informe que el Relator Especial para la promoción de la verdad, la justicia, la reparación y las garantías de no repetición, Pablo de Greiff, presentara en 2014 al Consejo de Derechos Humanos de la Asamblea General de Naciones Unidas, destacando la petición de una auténtica Política de Estado para con la Memoria, pero encontrando en cambio la "renuncia del Estado de asumir responsabilidad", así como una "indiferencia de las instituciones del Estado", y en consecuencia "una gran distancia entre las posiciones de la mayor parte de las instituciones del Estado por un lado, y por otro las víctimas y las asociaciones" ${ }^{24}$.

Una ausencia absoluta de cobertura, generadora en buena parte de una grave asimetría que desde el último lustro ha venido perjudicando claramente a las regiones españolas que a día de hoy aún carecen de una unidad administrativa específica de atención a las víctimas del franquismo, como sobre todo de un presupuesto específicamente destinado a acciones encaminadas a la recuperación de la Memoria Histórica, como actuaciones específicas en fosas y para la identificación genética, proyectos de investigación y divulgación, o a la promoción, declaración y señalamiento de los espacios de especial significación vinculados a la sublevación, la guerra civil y la dictadura como lugares de Memoria, aspectos estos que venían ya desarrollándose en otras regiones como Cataluña, País Vasco o Navarra, y antes que éstas, en Andalucía desde 1999, y refrendada, en marzo de este año, con la Ley de Memoria Histórica y Democrática de Andalucía ${ }^{55}$.

\footnotetext{
${ }^{52}$ La postura política y personal de Aznar ante el surgimiento del movimiento de Recuperación de la Memoria Histórica se muestra perfectamente en Guerrero, Rafael y Cruz, Salvador, "Política de la Memoria y desarrollo normativo en España", en Martínez, Fernando y Gómez, Miguel (coord.), La Memoria de todos... op. cit., pág. 210.

53 Resolución 47/133 de 18 de diciembre de 1992 de la Asamblea General de Naciones Unidas.

${ }^{54}$ Informe del Relator Especial sobre la promoción de la verdad, la justicia, la reparación y las garantías de no-repetición, Asamblea General de Naciones Unidas, 2014.

55 Ley 2/2017, de 28 de marzo de Memoria Histórica y Democrática de Andalucía, http://www.juntadeandalucia.es/boja/2017/63/1. Un texto, sobre el que a día de hoy se trabaja de forma intensa en el desarrollo normativo que lo nutra, y que ha servido de principal inspirador para los que, con similares características, y en distintos puntos de sus respectivos trámites parlamentarios, se están desarrollando en Aragón o Extremadura. De la misma forma, y para el caso de la Ley 52/2007, su desarrollo normativo específico en Martín, José Antonio y Escudero, Rafael,
} 
Quizás uno de los aspectos más criticados por parte del movimiento Memorialista a la Ley 52/2007 de Memoria Histórica sea que ésta no articulara que el Estado tomara verdaderamente las riendas, sobre todo en lo que a exhumaciones se refiere, es decir, que abandonara las subvenciones -lo que a la postre significaba delegar la potestad en familiares, colectivos Memorialistas y ayuntamientos- para hacerse cargo directamente de las intervenciones. Esto es, por ejemplo, lo que el Gobierno de Andalucía desarrolló desde 2014, con la creación de una partida específica destinada a estudios y trabajos técnicos, y que hoy engloba, desde los proyectos de investigación histórica previos a la fase arqueológica, hasta la localización, delimitación, exhumación, estudio antropológico y, siempre y cuando sea técnicamente posible, la propia identificación genética de los cuerpos recuperados ${ }^{56}$. Un hecho que, por otro lado, y desde una parte muy minoritaria del movimiento Memorialista, se entendió como una actitud excesivamente intervencionista, aunque nuestra opinión es que de lo que se trata es de una actitud garantista, por asegurar el apoyo de la administración andaluza, y no sólo en cuestiones meramente económicas, sino en su papel como mediadora con las administraciones provinciales ${ }^{57}$ y locales, o con el ámbito judicial.

Pero no es, como decimos, el caso del Gobierno central, que ha dejado morir de inanición la norma estatal y que ha esgrimido, como argumentario para su negacionismo, razones sobradamente conocidas como la del revanchismo y la venganza, el eufemismo de la reapertura de heridas o el lucro económico $^{58}$, y que si algo positivo han generado, ha sido el resurgir de una resistencia de familiares de víctimas y colectivos Memorialistas a una perpetuación del Olvido, como al menosprecio de su causa, ya fuera de forma directa o indirecta. ${ }^{59}$

Y todo ello en el mismo lustro en el que Baltasar Garzón fuera suspendido de sus funciones como juez de la Audiencia Nacional por el Consejo General del Poder Judicial, después de que el magistrado del Tribunal Supremo acordara la apertura de juicio oral contra él por presunta prevaricación, por la decisión de declararse competente para investigar los crímenes de la represión franquista como

Derecho y Memoria Histórica, Madrid, Trotta, 2008.

${ }^{56}$ Una medida refrendada con la firma, en julio de 2016, de un Convenio entre las consejerías de Salud y Cultura de la Junta de Andalucía y la Universidad de Granada, para la creación de un Banco de ADN de víctimas de la guerra civil y la posguerra en esta región.

Véase http://www.juntadeandalucia.es/organismos/cultura/actualidad/noticias/detalle/138857.html

${ }^{57}$ La más reciente de ellas la firma de un protocolo general entre la Junta de Andalucía y la Diputación de Cádiz para mantener y potenciar la colaboración en materia de actuaciones de Memoria Histórica y Democrática en la provincia gaditana. Véase http://www.dipucadiz.es/prensa/actualidad/Junta-y-Diputacion-acuerdan-reforzar-las-actuaciones-deMemoria-Historica/.

${ }^{58}$ Han sido numerosos los políticos españoles, en su gran mayoría vinculados al PP, que han criticado todas las las acciones desarrolladas en torno a la recuperación de la Memoria Histórica en nuestro país, si bien es cierto que ha sido Rafael Hernando, actual Portavoz del Grupo Parlamentario Popular en el Diputados, el que con más descrédito se ha referido a este proceso. La última de sus declaraciones en relación a este tema le valió una denuncia por parte de la Asociación para la Recuperación de la Memoria Histórica,

http://www.infolibre.es/noticias/politica/2017/03/07/victimas del franquismo denuncian rafael hernando por califica r entretenimiento busqueda familiares desaparecidos 62191 1012.html, si bien la Fiscalía General del Estado no encontró delito en su ofensa, http://www.publico.es/politica/fiscalia-ve-delito-burla-rafael.html

${ }^{59}$ Han sido numerosísimos los actos de dudosa ética democrática protagonizados tanto por el Gobierno como por altos responsables orgánicos del PP, manteniéndose tan de rabiosa actualidad que en los últimos días en que se revisaba este artículo han podido añadirse varios de señera importancia, como la participación de la Ministra de Defensa María Dolores de Cospedal en Málaga en un homenaje a un aviador franquista responsable de numerosos y sangrientos bombardeos en diversos pueblos de Andalucía desde 1936, la presencia del alcalde de Málaga como del ex Ministro de Justicia, Alberto RuizGallardón en el entierro en Nerja (Málaga) del que fuera ministro de Franco, José Utrera Molina mientras eran entonados los acordes del Cara al Sol o, en mayo mismo de 2017, la ofrenda floral ante una Cruz de los Caídos como colofón a la celebración de una jura de bandera civil en el municipio cordobés de Dos Torres. Así, respectivamente, el reflejo en prensa de los ejemplos expuestos puede verse en http://www.eldiario.es/andalucia/Cospedal-homenaje-franquista-bombardeoAndalucia 0 635186661.html, http://www.elperiodico.com/es/noticias/politica/cara-al-sol-funeral-utrera-molina-video5990713 y http://www.elplural.com/andalucia/2017/05/16/la-jura-de-bandera-que-acabo-con-un-homenaje-los-caidos-enpresencia-del-numero. 
crímenes de lesa humanidad desde su juzgado de la Audiencia Nacional ${ }^{60}$; de que en 2016 la Fiscalía General del Estado negara la asistencia a la jueza María Servini en la conocida como Causa argentina por la que se investigan delitos cometidos durante la guerra civil y la dictadura franquista ${ }^{61}$; de que el Grupo Parlamentario Popular en el Congreso de los Diputados se abstuviera en la Proposición No de Ley presentada por el PSOE en la Cámara Baja de exhumar del Valle de los Caídos los restos del dictador Franco o el impulso de la Ley 52/2007²; o de que el 19 de mayo de 2017 Pablo de Greiff volviera a recordar al Gobierno de Mariano Rajoy la obligación de atender de forma urgente los reclamos de las víctimas de la guerra civil y la dictadura. ${ }^{63}$

Es aquí donde este reclamo sobre el que redundaba De Greiff se vuelve resistencia -o posresistencia-, porque la resistencia vuelve, se mantiene, se fortalece, se perpetúa, mientras que existan restos de ese palpable delito para encontrar y enterrar de forma digna. De la misma forma la resistencia tiene sentido también en la medida en que hay injusticias a las que resistirse: el Gobierno central como los gobiernos regionales que no adoptan medidas en este sentido, sus políticos adscritos, el franquismo sociológico, la equidistancia procedente de la ignorancia o de la asimilación de un discurso histórico revisionista, o incluso la desmovilización sentimental de las generaciones posteriores al trauma, entre otras cosas por el éxito en muchos casos de la estrategia del régimen franquista de establecimiento del miedo y el silencio como forma de supervivencia, para sus vencidos coetáneos, como para sus generaciones postreras.

Pero la resistencia, transfigurada en deseo de reparación -dentro de todo lo que pueda abarcar un concepto que ya de por sí lleva aparejada la realidad de que ni las víctimas pueden ser devueltas a la vida, como no pueden ser devueltos su dinero, su patrimonio, o su trabajo- ha prevalecido felizmente sobre las imposturas del miedo y el silencio, sobre la falacia de los que ven en la víctima a un cazador de recompensas, o sobre la desidia que pudiera atribuirse a las segundas generaciones.

Luis Vega penetraba cada día desde agosto de 1936 y con 7 años, en el cementerio del municipio gaditano de Paterna de Rivera para buscar, en cada fosa abierta, los cuerpos de sus padres. No tuvo suerte, pero la historia familiar quedó transmitida de padre a hijo -de hijo a nieto-, convirtiéndose en una obligación moral. "¿Qué podría hacer yo por mi padre?... tomar el testigo, porque somos los nietos de los vencidos, pero no convencidos".

Señalaba Luis Vega que "no quería venganza”, como igualmente Elena Fernández, de Puerto Real e hija de uno de los 185 asesinados y arrojados a esta segunda mayor fosa exhumada en Andalucía, que insiste en que "yo no quiero venganza, sólo encontrar a mi padre y enterrarlo, y ahí acabará mi lucha".

Efectivamente no se trataba de venganza, ni revancha, ni lucro, sólo "un acto de justicia". De una justicia más social -y a la vez más efectiva- con las víctimas que punitiva con los victimarios, como insistía Ramón Delgado, sobrino nieto de "La Modestita" de Zalamea la Real, y que recibiría ese encargo moral de búsqueda y dignificación; lo mismo que José María Arauz, sobrino de una de las víctimas represaliadas en el cruento terror caliente de Cádiz, y que afirmaba que "cuando mi madre estaba en el hospital, muriéndose, me cogió de la mano y me dijo -no abandones nunca la búsqueda de mi hermano-, y no he parado"; o que Enrique Fernández, también de Puerto Real, y que insistía en que "no reclamo nada, cuatro huesos que podamos enterrar. Mi madre me lo encargó y aquí estoy".

Es la única forma de poder atenuar el dolor, si bien resulta imposible erradicarlo. “¿Dolor? Toda la vida. Y muero con la pena de no poder decir a esos que me hicieron tanto daño: ¿qué agenciaste, qué ganaste con dejarme solo?”, se lamentaba Antonio López, hijo de una de las 35 víctimas exhumadas en

\footnotetext{
${ }^{60}$ Véase http://elpais.com/elpais/2010/05/14/actualidad/1273825020 850215.html

${ }^{61}$ Véase http://www.elperiodico.com/es/noticias/politica/fiscalia-rechaza-auxiliar-jueza-argentilla-querella-crimenesfranquistas-5457860

${ }^{62}$ Véase http://www.europapress.es/nacional/noticia-congreso-pide-sacar-franco-valle-caidos-abstencion-pp-erc20170511140410.html

${ }^{63}$ Véase http://www.un.org/spanish/News/story.asp?newsID=37360
} 
el municipio sevillano de El Madroño, y que supo, muchas décadas después, y a través de las investigaciones de Juan José López, más casi de lo que pudieran contarle los testigos del genocidio. Algo parecido a lo que experimentara Andrés Molero, de la localidad cordobesa de Obejo, que señalaba cómo "me estoy enterando más en estos días de mi familia que en todo este tiempo atrás. Me cuentan ahora lo que tenían que haberme contado hace 60 años".

Las víctimas volvían a dar, una vez más, en la clave: conocer el pasado y abandonar el negacionismo, y Juan Manuel Fernández, de San Fernando (Cádiz), lo resumía perfectamente:

"Mientras este país no cumpla los derechos humanos no tendrá democracia completa. Exigimos justicia, no venganza. Dice un político que nos acordamos de nuestros muertos por subvenciones. Yo me he acordado de mi abuelo desde niño, a través de las lágrimas de mi madre".

Efectivamente, y como señala el filósofo Reyes Mate:

"si hoy, 80 años después, presentamos estos relatos como novedades, es porque aquella estrategia [de miedo y silencio] funcionó... y la sociedad debería entender que identificar a los desaparecidos y darles sepultura no es sólo un gesto de justicia para los muertos, sino de piedad para los vivos" $"$.

O lo que es lo mismo, "todas las sociedades deben asumir su pasado más pronto que tarde si realmente quieren avanzar" ", "porque los crímenes no prescriben, y olvidarlos nos convierten a todos en cómplices" ${ }^{\prime 66}$. Un antagonismo insoslayable para las necesidades de una sociedad actual de conocer, asimilar y concienciarse de la barbarie, para la no-repetición y para la construcción de un futuro de convivencia de mayor calidad democrática.

\section{Conclusiones}

El futuro de la Memoria en España pasa por entender su complejidad desde el punto de vista del análisis de nuestra historia reciente y desde la perspectiva de las víctimas ampliando el objetivo e incluyendo los derechos humanos como elemento clave para comprender los distintas actuaciones que se han llevado a cabo por la sociedad civil y por las administraciones públicas.

La trascendencia de la Memoria, más allá de las acciones de reparación, es que puede ser un dique para los totalitarismos -por eso se ideó y se impulsó el proyecto europeo común, hoy Unión Europea- si se afronta con valentía, con consensos y de la mano de los expertos -historiadores, arqueólogos, médicos forenses, sicólogos, artistas, etcétera-. Si el planteamiento es el uso político de la Memoria y la utilización de la misma como elemento de confrontación para reafirmar una identidad u objetivo partidista, la Memoria será un elemento más de la lucha política, un instrumento en manos del poder para utilizar el pasado como herramienta de supremacía. Algo, por cierto, poco novedoso como señala Gonzalo Pasamar cuando insiste que ya el siglo XIX fue fundamental para que el uso político de la Memoria:

“...se materializaría en numerosas tradiciones inventadas, con las que los Estados-naciones -junto a determinados sectores sociales- desplegaron un especial esfuerzo de legitimación o de búsqueda

\footnotetext{
${ }^{64}$ Estas citas de Manuel Reyes Mate como los testimonios inmediatamente anteriores, han sido extraídos de un trabajo periodístico, Premio Manuel Chaves Nogales 2016 de investigación periodística, y centrado en doce intervenciones en fosas de víctimas de la guerra civil en la comunidad andaluza, desarrolladas y sufragadas por el Gobierno de Andalucía, a través de la Dirección General de Memoria Democrática de la Consejería de Cultura. Baquero, Juanmi, Que fuera mi tierra. Intervenciones en fosas del franquismo en Andalucía. Anuario 2015, Sevilla, Extra! Comunicación, 2016. Mate, Reyes, Memoria de Auschwitz: Actualidad moral y politica, Madrid, Trotta, 2003.

${ }^{65}$ Giráldez, Francisco Javier, Política y Memoria...op. cit., pág. 14.

${ }^{66}$ Mate, Reyes, Memoria..., op. cit., pág. 67.
} 
de las señas de identidad, a través de actividades conmemorativas, construcción de edificios públicos, erección de monumentos y organización de la historia escolar" ${ }^{97}$.

Por otro lado, la Memoria se debe explicar desde una perspectiva local pero no puede entenderse desde la contextualización y visión transnacional. Dice Jordi Guixé que "la complejidad del trabajo memorístico se encuentra en la multiplicidad constante y la permanente mutación de sus conceptos, usos y consecuencias" ${ }^{\prime 68}$. Andalucía es un ejemplo de lo dicho: centenares de casos específicos que entremezclan problemáticas diferenciadas y enfoques distintos; exiliados a miles de kilómetros unos de otros, represaliados por los Tribunales de Responsabilidades Políticas, la persecución de los masones, las fosas comunes, el exilio, la monumentalizacion de los espacios de duelo, etcétera. La cantidad de acciones a realizar, lo potente de la represión, la tardanza en afrontarla o la capacidad de la sociedad de afrontar su propio pasado son aspectos que deben llevarnos a una reflexión serena para ver que caminos tomar con objeto de buscar una Memoria compartida por una amplia capa de la sociedad que no genere más tensiones sino que sea capaz de generar acuerdos.

Lo que está claro es que nos encontramos ante un pasado cada vez más presente que debe abordarse por parte de las administraciones públicas desde distintas perspectivas, entendiendo su complejidad, donde el equilibrio entre la ciencia histórica y los derechos humanos deben ser pilares fundamentales para conseguir que su asunción refuerce los valores de la democracia europea, cada vez más atacada desde posturas maximalistas.

\footnotetext{
${ }^{67}$ Pasamar, Gonzalo: “Los historiadores y el «uso público de la historia»: viejo problema y desafío reciente”, Ayer, 9/2003, Madrid, Marcial Pons, pág. 223.

${ }^{68}$ Guixé, Jordi (ed.): Past and power. Public Policies on Memory. Debates, from global to local, Universidad de Barcelona, 2016, pág. 257.
} 